\title{
Опыт использования карт трансформантного сопротивления при электрофациальном анализе по данным электроразведки в районе Вилюйской синеклизы
}

Кравченко А.А.

OП АО «РОСГЕО» «ИГП», Иркутск, a.zaynutdinova@inbox.ru

Иркутский национальный исследовательский технический университет

Аннотация. В работе приведены результаты использования электрофациального анализа в рамках составления геоэлектрической модели кембрийских рифогенных построек, развитых вдоль южного борта Вилюйской синеклизы. Цель работы заключалась в картировании органогенных построек, как отдельной фации, на этапе качественного анализа. Электрофациальный анализ проведён для кембрийских отложений двумя методами: путём интеграции электроразведочных данных (кривых STauHTau) в пакет Stratimagic и с помощью построения карт трансформантных сопротивлений, осуществляемого в программном обеспечении Geomodel. Результаты сопоставлены с существующей априорной информацией о фациальной дифференциации района. Сделаны выводы о кратности задаваемых электрофаций в пакете Stratimagic, необходимых для получения корректного результата и уровнях трансформантных сопротивлений, соответствующих отложениям ЗападноЯкутского барьерного рифа.

Ключевые слова: электроразведка, электрофациальный анализ, Вилюйская синеклиза, ЗападноЯкутский риф.

\section{Experience in using transformant resistance maps for electro-facial analysis based on electrical prospecting data in the area of the Vilyui syneclise}

\author{
Kravchenko A.A. \\ «Irkutsk Geophysical Division»,JSC «Rosgeo»,Irkutsk, a.zaynutdinova@inbox.ru \\ Irkutsk National Research Technical University
}

\begin{abstract}
The article presents the results of using electro-facies analysis in the framework of compiling a geoelectric model of the Cambrian reef structures developed along the southern flank of the Vilyui syneclise. The purpose of the work was to map organogenic structures as a separate facies at the stage of qualitative analysis. Electrofacies analysis was carried out for the Cambrian deposits by two methods: by integrating electrical exploration data (STauHTau curves) into the Stratimagic package and by constructing transformant resistance maps, carried out in the Geomodel software. The results are compared with the existing a priori information on the facies differentiation of the area. Conclusions are drawn about the multiplicity of the specified electrofacies in the Stratimagic package, necessary to obtain the correct result, and the levels of transformant resistivity corresponding to the sediments of the West Yakutsk barrier reef.
\end{abstract}

Key words: electrical prospecting, electro-facial analysis, Vilyui syneclise, West Yakutsk reef.

\section{Введение}

Современные тенденции развития методик производства геологоразведочных работ, иногда, требуют применения новых методик исследований и интерпретации результатов. Все чаще в интерпретации геофизических исследований используется подход фациального районирования, рассматривающий геологический разрез не только с точки зрения стратиграфического деления. Понятие «фация», включает в себя отложения, образованные в определенный период геологической истории, и в определенных условиях осадконакопления. Смена фациальной обстановки, выражается в изменении литологического состава и фаунистических остатков в пределах одной стратиграфической единицы (свиты, горизонта, толщи) (Крашенинников Г. Ф. ,1971). В исследуемом районе, рядом исследований выделены фациальные зоны, ознаменованные сменой типов отложений с доломитовых карбонатных, юго-запада платформы, на глинистые, северо-востока (Сухов С.С., 2017). Переходная зона между ними - рифовые органогенные постройки. Известно, что соли обладают 
высоким сопротивлением, по причине невозможности адсорбировать связанную воду, глинистые же отложения, имея ионно-ковалентную связь, отличаются низкими сопротивлениями. Изменение электрического сопротивление определяется характером кривой. Так, электрофациальный анализ, являющийся аналогом сейсмофациального, нацелен на районирование исследуемых площадей на фации, соответствующие определённому типу кривой ЗСБ.

\section{Методика исследования}

Для проведения электрофациального анализа использовались кривые ЗСБ, полученные на Ыгыатинской, Синской и Вилюйской площадях, распложенных вдоль южного и юго-западного бортов Вилюйской синеклизы. В первую очередь, был проведён электрофациальный анализ в пакете Stratimagic. Исходный полевой материал ЗСБ интегрируется в программный комплекс Stratimagic с помощью специализированных программ, разработанных обособленным подразделением АО «Росгеология» «Иркутское геофизическое подразделение», с заданным количеством электрофаций. Такой анализ подразумевает автоматическое фациальное районирование участка исследований по характеру изменения кривой в заданном интервале глубины (Кочукова В.А., Пашевин А.М, 2019). Заведомо известно, что регион включает 3 фациальные зоны с разными типами отложений и их петрофизическими свойствами, что должно отражаться на их электрической проводимости, сопротивлении, и самой кривой STauHTau, отображающей зависимость электрической проводимости S от глубины Н. В качестве глубинных интервалов исследования использовались сейсмические границы. Исследование проводилось для единого массива данных, включающих 3 площади. Для верхнего-среднего кембрия использовались границы: Синская площадь - G3dj-G1 in (джуктинская иниканская свиты), Ыгыатинская - Cha - II (чаргольская - билирская свиты). Для нижнего, использована граница от кровли фундамента до кровли билирской и иниканской свит. На Вилюйской площади отложения среднего-верхнего кембрия не расчленены по результатам сейсморазведки. Для нижнего кембрия, количество фаций равнялось трём, включая карбонатную платформу, риф и депрессионный бассейн. Нижнекембрийские отложения Ыгыатинской площади не анализировались, в связи с глубиной отложений, превышающей 5 км. Для верхнего-среднего кембрия количество заданных электрофаций равнялось 7, с учётом 4 априорно-известных зон (карбонатной платформы, рифа, предрифовой и открытого бассейна) и запаса в 3 электрофации в связи с присутствием на Вилюйской и Ыгыатинской площадях эффекта ВПИ (вызванной индукционной поляризации). Исследование проводилось для единого массива данных, включающих 3 площади, из представления, что они находились в единой зоне палеособытий и палеоклимата.

Второй метод электрофациального районирования, основан на зависимости проводимости, сопротивления и мощности горизонта. При известных значениях мощности слоя, полученных по результатам сейсморазведки $\Delta \mathrm{H}$, и значение приращения суммарной продольной проводимости $\Delta \mathrm{S}$, взятого с кривой StauHtau в отрезке $\Delta \mathrm{H}$, по формуле (1), получается трансформантное сопротивление $\rho$ для каждой кривой ЗСБ, используемое для построения карт.

$$
\rho=\mathrm{H} / \Delta \mathrm{S}
$$

Полученные сопротивления сохраняются в базу данных для каждого пикета ЗСБ, по которым в дальнейшем строится карта трансформантных сопротивлений.

\section{Результаты}

В результате исследования получены карты электрофаций и трансформантных сопротивлений. На картах трансформантных сопротивлений (рис. 1 а) просматривается фациальная зональность в области сочленения Вилюйской синеклизы и Аланской антеклизы, где для нижнего кембрия отмечается повышение сопротивления до 300 Ом* м по мере приближения к карбонатной платформе, для верхнего-среднего зона сопротивлений от 125 Ом*м картирует рифогенные постройки, от 70 Ом* м - предрифовая область. Помимо фациальной зональности, карты отображают области с присутствием эффекта вызванной индукционной поляризации (ВПИ) на Вилюйской и Ыгыатинской площадях (рис. 2), выражающегося в отрицательном приросте кривой StauHtau, в результате 


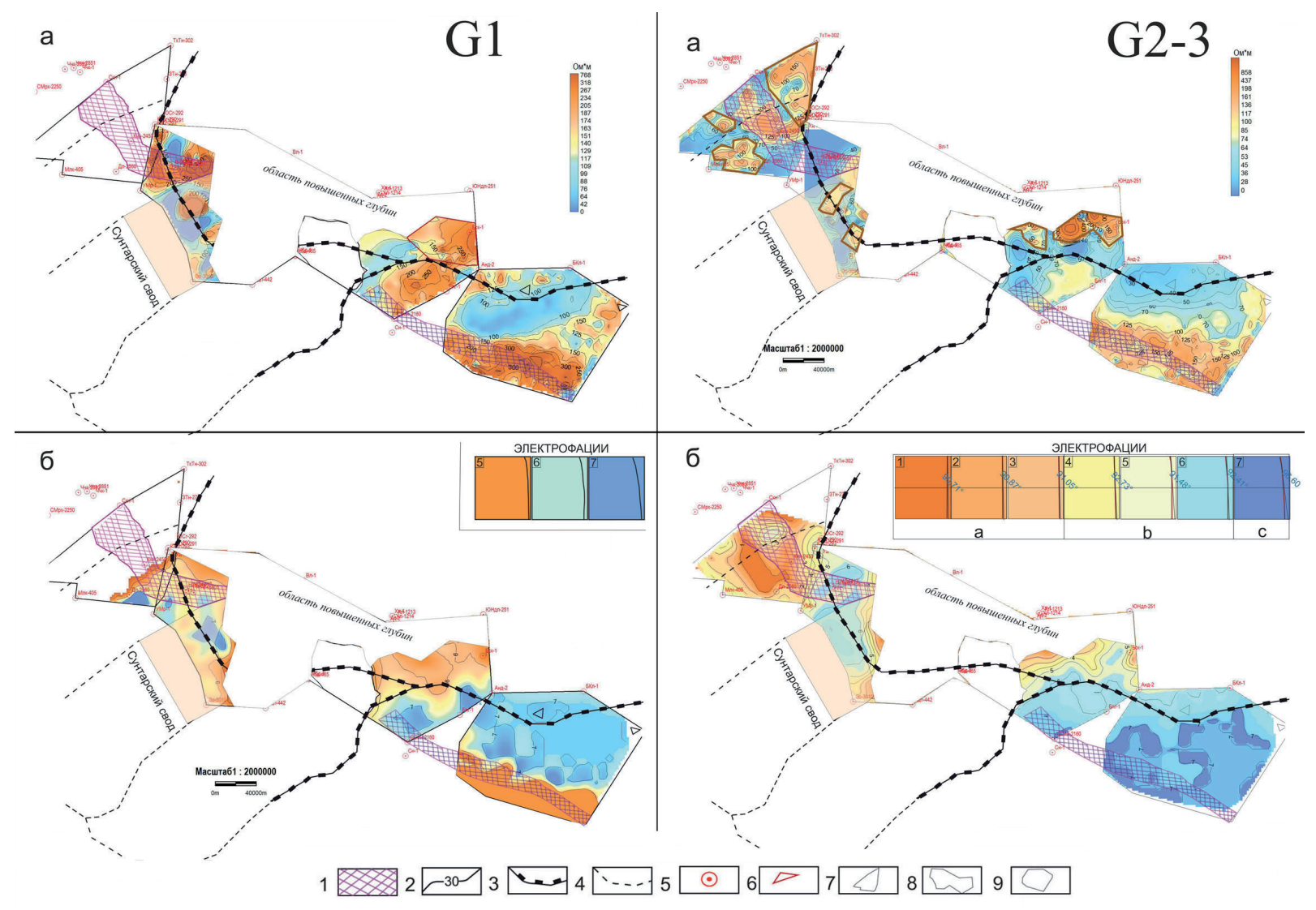

Рис. 1. Результаты электрофациального анализа нижнего и верхнего-среднего кембрия: a - карты трансформантных сопротивлений, $\mathrm{b}$ - электрофациальный анализ Stratimagic.

1 - априорная область развития рифов, 2 - изолинии сопротивлений/электрофаций, 3 - границы Вилюйской синеклизы и Алданской антеклизы, 4 - надпорядковые структуры, 5 - скважины глубокого бурения, 6 - области проявления ВПИ, 7 - Ыгыатинская площадь, 8 - Вилюйская пл., 9 - Синская пл.

Fig. 1. Results of electrofacies analysis of the Lower and Upper-Middle Cambrian: a - transformant resistance maps, $\mathrm{b}-$ Stratimagic electrofacial analysis.

1 - a priori area of reef development, 2 - isolations of resistors / electrofacies, 3 - boundaries of the Vilyui syneclise and Aldan anteclise, 4 - superorder structures, 5 - deep drilling wells, 6 - zones of influence of induction-induced polarization, 7 - Ygyatinskaya area, 8 - Vilyuiskaya area., 9 - Sinskaya area.

чего полученные сопротивления завышаются (Компаниец С.В. и др., 2019). Присутствие эффекта ВПИ осложняет процесс интерпретации, и устраняется на этапе подбора моделей для полевых кривых, проведения инверсии.

На картах электрофаций, полученных в программе Stratimagic (рис.1, б), карбонатная фациальная зональность отмечена только на Синской площади в интервале нижнего кембрия. В южной части площади закартирована фация карбонатной платформы, предрифовая и глубоководные фации не дифференцированы, что вероятно связано с недостаточным заданным количеством электрофаций. Интервал верхнего-среднего кембрия, также не отразил дифференциацию, полученную на карте трансформантного сопротивления, вероятно, вероятно под влиянием кривых Ыгыатинской площади, осложнённых ВПИ. Стоит отметить, что на картах трансформантного сопротивления, эффект отражается локально, так как нивелируется разнесенными точками, поскольку ВПИ в большей степени подвержены именно соосные пункты наблюдений. Таким образом, установлено что для получения адекватной картины распределения электрофаций, в случае использования пакета Stratimagic, необходимо проводить анализ для локальных территорий, с искусственно увеличенным количеством задаваемых электрофаций. С учётом вышесказанного, проведен анализ для 



Рис. 2. Проявление ВПИ на кривых StauHtau и RhoTau на диполе Вилюйской площади.

Fug. 2. Manifestation of induction-induced polarization on the StauHtau and RhoTau curves on the dipole of the Vilyui area.



Рис. 3. Электрофациальное районирование Синской площади в пакете Stratimagic.

Fig. 3. Electrofacial zoning of Sinskaya area in the Stratimagic package.
Синской площади в интервале пермских отложений и верхнего-среднего кембрия (рис. 3). Количество задаваемых фаций увеличено до 11. В таких случаях, для дальнейшей корреляции с геолого-геофизической информацией, имеет смысл осуществлять группировку фаций.

В работе предложена группировка по принципу границ наибольших отклонений углов касательных к участкам кривых. Среднее отклонение составило $1.38^{\circ}$. Так, значительным отклонением можно положить значение, превышающее 2 . Учитывая влияние пермских проводящих отложений на севере, фация с, выделяемая как глубоководная, включает фации «с 1» и «с 2», отличающиеся проводимостью, за счет верхней части разреза. Фация «с» и «b», относятся к областям сноса построек, и отличаются по причине разных коллекторских свойств. Фация «а» выделена как карбонатная, обладает наименьшим углом касательной к кривой StauHtau, и соответственно, наиболее высокоомная.

\section{Выводы}

На участках южного борта Вилюйской синеклизы, по результатам комплексного электрофациального анализа, закартирована область фациального перехода от глубоководных глинистых отложений к карбонатным. Наиболее достоверные результаты получены методом построения карт трансформантных сопротивлений, с помощью которого выделена зона сноса средне-верхнекембрийских отложений в области сочленения Алданской антеклизы и Вилюйской синеклизы, выделенная уровнем сопротивления от 70 до 125 Ом*м.

Электрофациальное районирование программой Stratimagicв пределах трёх площадей, не отображает реальной фациальной картины, вероятно, в связи с влиянием эффекта ВПИ на используемые соосные пункты наблюдения Ыгыатинской и Вилюйской площадей и недостаточным за- 
данным количество электрофаций Таким образом, установлено, что подобный анализ следует проводить на локальных участках без влияния эффекта ВПИ, с искусственным увеличением количества предполагаемых фациальных зон. В дальнейшем, увеличенное количество фаций может быть сгруппировано по принципу установки границ наибольших отклонений углов касательных к участкам кривых.

Можно подытожить, что метод построения карт трансформантных сопротивлений наиболее прост в использовании и применителен для дальнейшей интерпретации данных, поскольку выходным значением являются трансформантные сопротивления, также определяющие участки осложнённого полевого материала, отличающиеся своей локальностью от аномалий, вызванных фациальными разностями.

\section{Литература}

1. Компаниец С.В., Кожевников Н.О., Мурзина Е.В., Емельянов В.С. Интерпретация данных зондирования становлением поля в ближней зоне с учетом индукционно-вызванной поляризации при площадных нефтегазопоисковых исследованиях на юге Сибирской платформы // Известия Сибирского отделения секции наук о Земле Российской академии естественных наук. Геология, разведка и разработка месторождений полезных ископаемых. 2019. Т. 42. № 2. С. 151-164. DOI: 10.21285/2541-9455-2019-42-2-151-164.

2. Кочукова В.А., Пашевин А.М. Методика интерпретации электромагнитных зондирований в геоэлектрических условиях юга Сибирской платформы (электрофациальный анализ) // Науки о Земле и недропользование. 2019. Т. 42. №. 2 (67). С. 165-175.

3. Крашенинников Г.Ф. Учение о фациях. Учеб. пособие. М. Изд-во: Высшая школа. 1971. 368 с.

4. Стогний В.В., Коротков Ю.В. Поиск кимберлитовых тел методом переходных процессов // Новосибирск. Изд-во: Малотиражная типография D. 2010. Т. 2. С. 2010. 121 с.

5. Сухов С.С. О роли фациально-седиментологических критериев в реконструкции кембрийских палеобассейнов востока Сибирской платформы // Современные проблемы седиментологии в нефтегазовом инжиниринге: труды III Всероссийского научно-практического седиментологического совещания, 10-12 апреля 2017. Томск. С. 209-214. 